\title{
Complete percutaneous coronary intervention revascularization after unsuccessful surgical revascularization with allergy to aspirin
}

\author{
Davor Richter*, Krešimir Štambuk, Tomislav Šipić, Hrvoje Stipić \\ Clinic for Cardiovascular Disease Magdalena, Krapinske Toplice, Croatia
}

\begin{abstract}
A 72-year-old diabetic (type II) patient with multivessel coronary artery disease (distal LMCA, critical LAD/D2 bifurcation stenosis, proximal OM1 stenosis and ostial PD of RCA) and normal systolic left ventricular function underwent surgical revascularization (9/2012). Since a long segment of LAD was intramural, LIMA was found to be too short so patient obtained two venous grafts - on LAD and diagonal branch. Marginal branches as well as PD were found not suitable for grafting. 48 hours later ST elevation in inferior leads was observed and urgent angiography was carried out. Grafts to LAD and D2 had a TIMI III flow, showing LAD antero- and retrogradely but with a stenosis of $L A D$ at the point of junction. Venous graft to D2 fills retrogradely the artery as well as the median part of the LAD. In addition native $D 2$ is shown to be significantly narrowed distally to the point of graft junction. Probable cause of the ECG changes were due do ostial PD stenosis and being a smaller caliber vessel and patient haemodinamically stable, patient was treated conservatively, than later discharged. But at outdoor control silent ischaemia was documented and new angiography performed showing disfunction of the graft to distal LAD and still normally functioning graft to D2 but with stenosis as previous. We considered complete secondary revascularization but had to face a known allergy to aspirin and the need of effective dual antiplatelet therapy in a diabetic. Our strategy
\end{abstract}

was to divide interventions in two steps - firstly we did $\mathrm{PCl}$ on LAD with 2 DES in proximal and median segment (Xience $2,5 \times 28+3,0 \times 18$ ) and OM with 1 BMS (Yukon 3,0x16) under the protection of enoxaparine which was changed to varfarine and $140 \mathrm{mg}$ of clopidogrel which was substituted by ticagrelor. The primary result was excellent. In the second act intervention on LMCA and D2 via venous graft (DES) is considered after possible desensibilization treatment for aspirin allergy that poses us now the greatest problem.

KEYWORDS: percutaneous coronary intervention, coronary artery bypass graft, aspirin.

\section{Literature}

1. Morrison DA, Sethi G, Sacks J, et al. Percutaneous coronary intervention versus repeat bypass surgery for patients with medically refractory myocardial ischemia: AWESOME randomized trial and registry experience with post-CABG patients. J Am Coll Cardiol. 2002;40(11):1951-4.

2. Brilakis ES, Rao SV, Banerjee S, et al. Percutaneous coronary intervention in native arteries versus bypass grafts in prior coronary artery bypass grafting patients: a report from the National Cardiovascular Data Registry. JACC Cardiovasc Interv. 2011;4(8):844-50.

3. Ortega-Loayza AG, Raza S, Minisi AJ, et al. Aspirin desensitization/challenge in 3 patients with unstable angina. Am J Med Sci. 2010;340(5):418-20. 